\title{
Correlation Between Visual Prostate Symptom Score and Uroflowmetry Parameters in Patients with Benign Enlargement of Prostate
}

\author{
Gupta DK ${ }^{1}$, Gupta $\mathrm{S}^{2}$, Jha N
}

\begin{abstract}
Background: Benign enlargement of prostate (BEP) needs treatment based on evaluation of symptom scoring among which International prostate symptom score (IPSS) is the standard one but carries difficulty in completion of the form. A visual prostate symptom score (VPSS) can evaluate the symptom with similar efficacy in a larger population with lower education. Aim of the study: The study was aimed to evaluate the correlation of the VPSS with uroflowmetry parameters. Materials and Methods. Men provisionally diagnosed as BEP were requested to complete the IPSS and VPSS, consisting of pictograms to evaluate urinary frequency, nocturia, force of the stream and quality of life. The maximum (Qmax) and average urinary flow rate (Qave), voided volume (VV) and post-void residual (PVR) urine volumes were measured. Statistical analysis was performed using the chi square test and Spearman's tests. Results. The study included 45 men (mean age 66 years, range 50-78 yrs.), with median prostate weight of $40 \mathrm{gm}$. One fourth of the patients were illiterate. Majority of the patients could complete VPSS without physician's assistance (46\%). With mean voided volume of $273 \mathrm{ml}$, mean Qmax and Qave were 10.8 and 5.7, respectively. There was significant negative correlation of VPSS with Qmax ( $r=-0.435, p=0.003)$ and negative correlation of IPSS with Qmax, though insignificant $(r=-0.1 .05$, $\mathrm{p}=0.4$ ). Respective components of IPSS and VPSS also correlated significantly. Conclusion: The VPSS is equivalent to the IPSS in terms of correlation with uroflowmetry parameters and can therefore be used instead of the IPSS to evaluate LUTS in men with benign enlargement of prostate.
\end{abstract}

Key words: Benign enlargement of prostate, international prostate symptom score, visual prostate symptom score

\section{INTRODUCTION}

The prevalence of lower urinary tract symptoms (LUTS) due to benign enlargement of prostate (BEP) in elderly population is as high as $90 \%$ by age $85^{1}$. It includes voiding and storage LUTS and its impact on quality of life is highly variable. It is the patient's perception of severity that determines the choice of therapy ${ }^{2,3}$. The pressure-flow study (PFS) is the reference standard for evaluating bladder outlet obstruction (BOO) due to $B E P^{4}$. However, it is invasive and not practical in all patients. The international prostate symptom score (IPSS) is the standard questionnaire applied internationally, which can convert subjective symptoms into objective scores. It helps in formulating treatment plan by categorizing the patients into different severity groups ${ }^{5,6}$.

The IPSS was meant to be a self administered tool to be used even in primary care setting. However, large proportion of

1. Dr. Dipesh Kumar Gupta

2. Dr. Sharmila Gupta

3. Dr. Niraj Jha

Address for correspondence:

Dr. Dipesh Kumar Gupta

Department of Urology

Nepalgunj Medical College Teaching Hospital,

Nepalgunj, Banke, Nepal

Email: drdipeshgupta@yahoo.com patients found it difficult to comprehend especially by those with lower educational level ${ }^{7}$. As a result, many scoring systems have been developed but not satisfactorily applied.

Visual prostate symptom score (VPSS) is a pictogram based scoring system aimed to address difficulties encountered

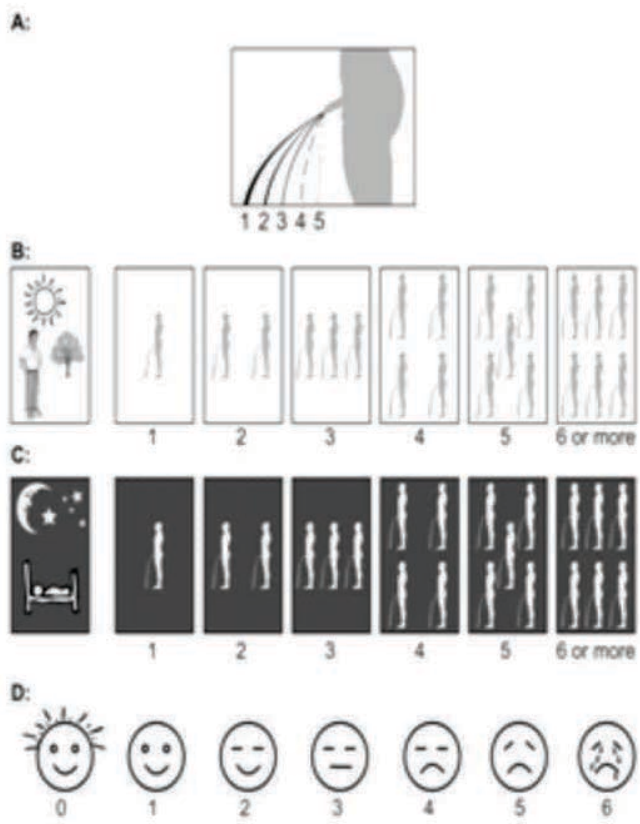

Figure 1: Visual Prostate Symptom Score 
during use of IPSS. It uses four of the questions in IPSS i.e. frequency, nocturia, weak stream and quality of life (QoL). Van Der Walt et al found it equally efficient in identifying symptom severity. It could be completed by majority of the patients, also by those with lower education level ${ }^{8}$. It had good correlation with IPSS and uroflowmetry parameters ${ }^{8-10}$.

We aimed to evaluate the correlation between the VPSS and IPSS and non-invasive uroflowmetry parameters in men with benign enlargement of prostate.

\section{MATERIALS AND METHODS}

This was a prospective study done at Nepalgunj Medical College, a tertiary care center in Mid Western part of Nepal. Patients presenting with LUTS who were provisionally diagnosed as BEP were enrolled. A total of 45 patients were included over a period of ten months from November 2014 to August 2015.

After full medical history was obtained, digital rectal examination, urine analysis, serum prostate-specific antigen (PSA) and creatinine measurement, and ultrasonography were performed to evaluate the urinary system. Ultrasonography (USG) was also used for residual urine measurement. The peak urinary flow rate (Qmax), average urinary flow rate (Qave), and voided volume were measured using a Nidhi flow Uroflowmeter, 814. Patients were requested to complete the Nepali version of IPSS questionnaire, which consists of 7 questions: Q1, incomplete emptying; Q2, frequency; Q3, intermittency; Q4, urgency; Q5, weak stream; Q6, straining; and Q7, nocturia including additional question on quality of life $(\mathrm{QoL})$. The patients were also requested to complete the VPSS questionnaire. The VPSS consists of 4 pictograms to evaluate the following domains: Q1, force of urinary stream; Q2, frequency; Q3, nocturia, and Q4, QoL of patients.

The chi-square test was used for contingency table analysis to evaluate factors associated with how the respondent completed the IPSS and VPSS questionnaires. Spearman's test was used for correlation analysis between the IPSS and the VPSS and the uroflowmetry parameters. A two-tailed P-value $<0.05$ was accepted as statistically significant.

\section{RESULTS}

Mean age of the patients was $66 \pm 7.07$ years with a range of 50 to 78 years. Most of them were in their 60 s (44\%). Median prostatic weight was $40 \mathrm{gm}$. as determined by ultrasonography. Median duration of LUTS was 15 months (range 4-60 months). Other characteristics are as described in Table I.

Number of patients who were literate was 30 with median grade of schooling of eighth standard (Figure 2). Farmers were the main patient group (53\%).

\begin{tabular}{|l|c|c|c|}
\hline Variable & Mean & SD & Range \\
\hline Prostate wt $(\mathrm{gm})$ & 47 & 25 & $27-138$ \\
\hline S. Creatinine $(\mu \mathrm{mol} / \mathrm{l})$ & 94.04 & 10 & $75-120$ \\
\hline S. PSA $(\mathrm{ng} / \mathrm{ml})$ & 1.8 & 0.9 & $0.4-4.31$ \\
\hline
\end{tabular}

Table I: Patient's characteristics and laboratory values

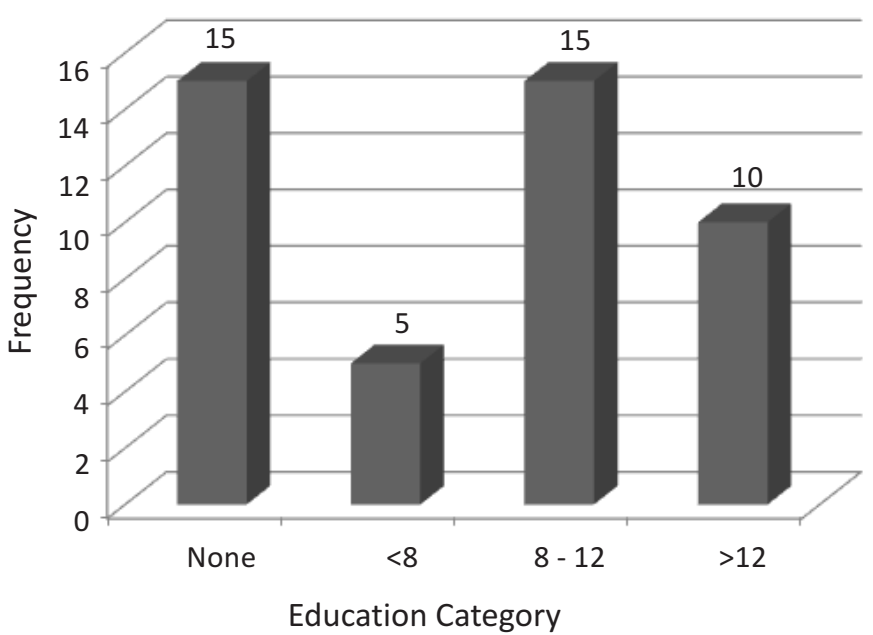

Figure 2: Educational status of the patients

Overall the patients who could complete VPSS alone without anyone's assistance was $46 \%$. Medical personnel had to assist in $24 \%$ of the cases. On the other hand, $75 \%$ of the cases required the assistance of a doctor while completing IPSS (Table II).

\begin{tabular}{|l|c|c|c|}
\hline \multicolumn{1}{|c|}{ Completion by } & $\begin{array}{c}\text { IPSS } \\
\mathbf{n}(\%)\end{array}$ & $\begin{array}{c}\text { VPSS } \\
\mathbf{n}(\%)\end{array}$ & p-value \\
\hline Alone & $8(17.8)$ & $21(46.7)$ & \multirow{2}{*}{$<0.001$} \\
\cline { 1 - 3 } Family member & $3(6.7)$ & $13(28.9)$ & \multirow{2}{*}{ Doctor } \\
\hline
\end{tabular}

Table II: Requirement of assistance while completing IPSS and VPSS

Mean IPSS in the patients was $23 \pm 7.2$ with mean IPSS QoL of 4.6 61 . 4 . Similarly, mean VPSS was $11.8 \pm 2.6$ with mean VPSS QoL of $3.5 \pm 1.6$. With median voided volume of $241 \mathrm{ml}$. in uroflowmetry, Qmax was $10.8 \mathrm{ml} / \mathrm{s}$. Post procedure USG showed a mean PVRU of $76.8 \mathrm{ml}$. (Table III).

Age correlated significantly with VPSS $(r=+0.440 ; p=0.002)$ but failed to do so with IPSS $(r=+0.023 ; p=0.883)$. Age showed correlation with prostate weight as well $(r=+0.426 ; p=0.004)$. There was negative correlation with Qmax though insignificant $(r=-0.244 ; p=0.106)$. 
Gupta et al.: Correlation Between Visual Prostate Symptom Score and Uroflowmetry Parameters in Patients with Benign Enlargement of Prostate

\begin{tabular}{|l|c|c|c|}
\hline $\begin{array}{l}\text { Uroflowmetry } \\
\text { parameters }\end{array}$ & Mean & SD & Median \\
\hline Voided Volume $(\mathrm{ml})$ & 273.09 & 133.168 & 241 \\
\hline Qmax $(\mathrm{ml} / \mathrm{s})$ & 10.80 & 2.20 & 11 \\
\hline Qave $(\mathrm{ml} / \mathrm{s})$ & 5.69 & 1.975 & 6 \\
\hline PVRU $(\mathrm{ml})$ & 76.80 & 67.299 & 60 \\
\hline
\end{tabular}

Table III: Uroflowmetry parameters

Negative correlation was seen between total VPSS and Qmax $(p=0.003)$ and Qave. Question on weak stream in VPSS (Q1) also correlated negatively with Qmax, though the result was not significant. Similarly, IPSS also correlated negatively with Qmax and Qave but the result was statistically not significant. Importantly, there was significant positive correlation between total VPSS and total IPSS. Similarly, IPSS QoL and VPSS QoL correlated positively (Table IV).

\begin{tabular}{|l|c|c|}
\hline Parameters & $\begin{array}{c}\text { Spearman's } \\
\text { correlation } \\
\text { coefficient }\end{array}$ & p value \\
\hline Total VPSS vs Qmax & -0.435 & 0.003 \\
\hline Total IPSS vs Qmax & -0.105 & 0.491 \\
\hline Total VPSS vs Qave & -0.163 & 0.284 \\
\hline Total IPSS vs Qave & -0.010 & 0.946 \\
\hline VPSS Q1vs Qmax & -0.232 & 0.125 \\
\hline IPSS Q5 vs Qmax & -0.262 & 0.082 \\
\hline Total VPSS vs VPSS QoL & +0.398 & 0.007 \\
\hline Total IPSS vs IPSS QoL & +0.447 & 0.002 \\
\hline Total IPSS vs Total VPSS & +0.366 & 0.013 \\
\hline IPSS QoL vs VPSS QoL & +0.512 & $<0.0001$ \\
\hline Frequency VPSS vs Frequency IPSS & +0.429 & 0.003 \\
\hline Nocturia IPSS vs Nocturia VPSS & +0.594 & $<0.0001$ \\
\hline Weak Stream IPSS vs WS VPSS & +0.296 & 0.048 \\
\hline
\end{tabular}

Table IV: Spearman's correlation for IPSS and VPSS

\section{DISCUSSION}

While the IPSS is the internationally recognized standard tool for assessment of patients with BEP, lower education level of the patients hinders their appropriate assessment and treatment $^{11-13}$. Newly devised VPSS aims to address the difficulties associated with the use of IPSS and has greatly succeeded in that ${ }^{8,9,14,15}$. In current study, mean IPSS and VPSS were 23 and 11.84, respectively. Higher score of IPSS denotes severe symptoms which more often requires operative treatment $^{16}$.

Pressure flow study is considered the gold standard for evaluation of bladder outlet obstruction where indicated.
However, it's not feasible in all and simple method of uroflowmetry can well correlate with the parameters and it is convenient. Uroflowmetry and PVRU measurements are simpler than urodynamic study (UDS) and are recommended by the European Association of Urology (EAU) for use in the initial evaluation ${ }^{17}$. In a study by Wadie et al, mean Qmax was $11.8 \mathrm{ml} / \mathrm{s}$ with Qave of $6.07 \mathrm{ml} / \mathrm{s}$ and PVRU of $43.3 \mathrm{ml}^{6}$. El Din Ke et al studied 71 men and showed mean Qmax of 10.9 $\mathrm{ml} / \mathrm{s}$ and PVRU of $56 \mathrm{ml}^{18}$. Similarly, in a study of 219 Japanese men, Homma et al found Qmax of $5.6 \mathrm{ml} / \mathrm{s}$ and PVRU of $106 \mathrm{ml}^{19}$. Present study shows similar uroflowmetry result with mean Qmax of $10.8 \mathrm{ml} / \mathrm{s}$ and mean PVRU of $76 \mathrm{ml}$.

Uroflowmetry as a component of pressure flow study has been established method to evaluate objective parameters in $\mathrm{BOO}^{16}$. The correlation of IPSS with these objective parameters have been largely studied. Though weak and insignificant, present study shows negative correlation of IPSS with uroflowmetry parameters (Qmax and Qave). Girman et al performed an analysis of 466 men 40-79 years old, and reported significant negative correlation of IPSS with Qmax $(p<0.001)^{20}$.

In present study, VPSS shows negative as well as significant correlation with Qmax and Qave. The results are similar with the studies by van der Walt and Wessels $\mathrm{SG}^{8,9}$. There is positive correlation between specific questions of IPSS related to frequency, nocturia and weak stream and the respective components of VPSS.

\section{CONCLUSION}

The VPSS is equivalent to the IPSS in terms of correlation with uroflowmetry parameters and can therefore be used instead of the IPSS to evaluate LUTS in men with benign enlargement of prostate.

\section{REFERENCES}

1. Thorpe A, Neal D. Benign prostatic hyperplasia. Lancet. 2003; 361(9366):1359-67.

2. Garraway WM, Russell EB, Lee RJ, Collins GN, McKelvie GB, Hehir $M$, et al. Impact of previously unrecognized benign prostatic hyperplasia on the daily activities of middle-aged and elderly men. Br J Gen Pract. 1993; 43(373):318-21.

3. Roberts RO, Rhodes T, Panser LA, Girman CJ, Chute CG, Oesterling $\mathrm{JE}$, et al. Natural history of prostatism: worry and embarrassment from urinary symptoms and health care-seeking behavior. Urology. 1994; 43(5):621-8.

4. Abrams P. In support of pressure-flow studies for evaluating men with lower urinary tract symptoms. Urology. 1994; 44(2):153-5.

5. Mebust W RRSFVA. Correlations between pathology, clinical symptoms and the course of the disease. Proceedings of the International Consultation on Benign Prostatic Hyperplasia Geneva:WHO. 1991:51-62.

6. Kaplan SA. Update on the american urological association guidelines for the treatment of benign prostatic hyperplasia. Rev Urol. 2006; 8 Suppl 4:S10-7. 
7. Cam K, Akman Y, Cicekci B, Senel F, Erol A. Mode of administration of international prostate symptom score in patients with lower urinary tract symptoms: physician vs self. Prostate Cancer Prostatic Dis. 2004; 7(1):41-4.

8. Van der Walt $\mathrm{CL}$, Heyns $\mathrm{CF}$, Groeneveld $\mathrm{AE}$, Edlin RS, van Vuuren SP. Prospective comparison of a new visual prostate symptom score versus the international prostate symptom score in men with lower urinary tract symptoms. Urology. 2011; 78(1):17-20.

9. Wessels SG, Heyns CF. Prospective evaluation of a new visual prostate symptom score, the international prostate symptom score, and uroflowmetry in men with urethral stricture disease. Urology. 2014; 83(1):220-4.

10. Heyns CF, van der Walt CL, Groeneveld AE. Correlation between a new visual prostate symptom score (VPSS) and uroflowmetry parameters in men with lower urinary tract symptoms. S Afr Med J. 2012; 102(4):237-40.

11. MacDiarmid SA, Goodson TC, Holmes TM, Martin PR, Doyle RB. An assessment of the comprehension of the American Urological Association Symptom Index. J Urol. 1998; 159(3):873-4.

12. Netto Junior NR, de Lima ML. The influence of patient education level on the International Prostatic Symptom Score. J Urol. 1995; 154(1):97-9.

13. Johnson TV, Abbasi A, Ehrlich SS, Kleris RS, Schoenberg ED, OwenSmith $A$, et al. Patient misunderstanding of the individual questions of the American Urological Association symptom score. J Urol. 2008; 179(6):2291-4; discussion 4-5.

14. Ceylan Y, Gunlusoy B, Degirmenci T, Kozacioglu Z, Bolat D, Minareci $S$. Is new visual prostate symptom score useful as International Prostate Symptom Score in the evaluation of men with lower urinary tract symptoms? A prospective comparison of 2 symptom scores in Turkish society. Urology. 2015; 85(3):653-7.

15. Selekman RE, Harris CR, Filippou P, Chi T, Alwaal A, Blaschko SD, et al. Validation of a Visual Prostate Symptom Score in Men With Lower Urinary Tract Symptoms in a Health Safety Net Hospital. Urology. 2015; 86(2):354-8.

16. Wadie BS, Ibrahim EH, de la Rosette JJ, Gomha MA, Ghoneim MA. The relationship of the International Prostate Symptom Score and objective parameters for diagnosing bladder outlet obstruction. Part I: when statistics fail. J Urol. 2001; 165(1):32-4.

17. De la Rosette JJ, Alivizatos G, Madersbacher S, Perachino M, Thomas D, Desgrandchamps $F$, et al. EAU Guidelines on benign prostatic hyperplasia (BPH). Eur Urol. 2001; 40(3):256-63; discussion 64.

18. El Din KE, Koch WF, de Wildt MJ, Kiemeney LA, Debruyne FM, de la Rosette JJ. Reliability of the International Prostate Symptom Score in the assessment of patients with lower urinary tract symptoms and/or benign prostatic hyperplasia. J Urol. 1996; 155(6):1959-64.

19. Homma Y, Yamaguchi T, Kondo Y, Horie S, Takahashi S, Kitamura T. Significance of nocturia in the International Prostate Symptom Score for benign prostatic hyperplasia. J Urol. 2002; 167(1):172-6.

20. Girman CJ, Jacobsen SJ, Guess HA, Oesterling JE, Chute CG, Panser LA, et al. Natural history of prostatism: relationship among symptoms, prostate volume and peak urinary flow rate. J Urol. 1995; 153(5):1510-5. 